Fermilab-TM-2145

\title{
Measured Longitudinal Beam Impedance of Booster Gradient Magnets
}

James L. Crisp and Brian J. Fellenz

March 22, 2001

\section{INTRODUCTION}

The Booster gradient magnets have no vacuum pipe which forces the beam image current to flow along the laminated pole tips. Both D and F style magnets were measured with a stretched wire to determine the longitudinal beam impedance caused by these laminations. Results are compared to calculations done 30 years ago. The inductive part of the magnet impedance is interesting because it partially compensates for the negative inductance effects of space charge on the beam. An R/L circuit consisting of $37 \mathrm{~K} \cdot$ in parallel with between 40 and $100 \mathrm{uH}$ is a reasonable approximation to the total impedance of Booster magnet laminations.

\section{THE MEASUREMENT}

A 30 gauge (.0100") tin plated copper wire was stretched through the magnet and an HP $8753 \mathrm{E}$ network analyzer was used to measure S21, the attenuation through the magnet. The characteristic impedance of the wire is estimated below for wire diameter $\mathrm{d}$ and pole tip spacing h:

$$
\begin{aligned}
& Z_{0} \approx \frac{1}{2 \pi} \sqrt{\frac{\mu_{0}}{\varepsilon_{0}}} \ln \left(\frac{4 h}{\pi d}\right) \\
& \text { F magnet: } \quad Z \mathrm{o}=321 \bullet \text { for } \mathrm{h}=1.656 " \\
& \text { D magnet: } \quad \mathrm{Zo}=338 \bullet \text { for } \mathrm{h}=2.188^{\prime \prime}
\end{aligned}
$$

The characteristic impedance was matched to 50 - with a resistive $\mathrm{L}$ pad at each end of the wire. The pad was made with four $220 \bullet$ resistors to ground and one $300 \bullet$ resistor in series. All resistors were $1 / 4$ watt carbon. The measured attenuation through both pads agrees with calculation at $-27.57 \mathrm{db}$. The small amount of frequency structure related to the length of the wire (half wavelength at $50 \mathrm{MHz}$ ) demonstrates the $326 \bullet \mathrm{L}$ pads are well matched to the characteristic impedance of the wire for both $F$ and $D$ magnets.

Losses from the matching L pads and skin effect losses along the wire were used to correct the measurement. As an example, the center wire contributes only $.29 \mathrm{db}$ from skin effect losses to the $4.9 \mathrm{db}$ total loss through the magnet at $400 \mathrm{MHz}$. 
Magnet sagitta causes the stretched wire to deviate from the center by \pm .50 " in an F magnet and \pm .43 " in a D magnet. The characteristic impedance along the wire changes by less than $1 \%$ from sagitta. The wire is 126 " long and sags by about $1 / 8$ " vertically. The effect of these errors are considered small and ignored in this analysis.

The cutoff frequency for the propagation of microwave modes is $870 \mathrm{MHz}$ in both the $\mathrm{F}$ and $\mathrm{D}$ magnets. This was determined by replacing the stretched wire with 1 " stubs at each end and measuring the coupling between them. The stretched wire technique cannot be used to measure the impedance of Booster Magnets above $870 \mathrm{MHz}$.

\section{coupling through F\&D magnets}

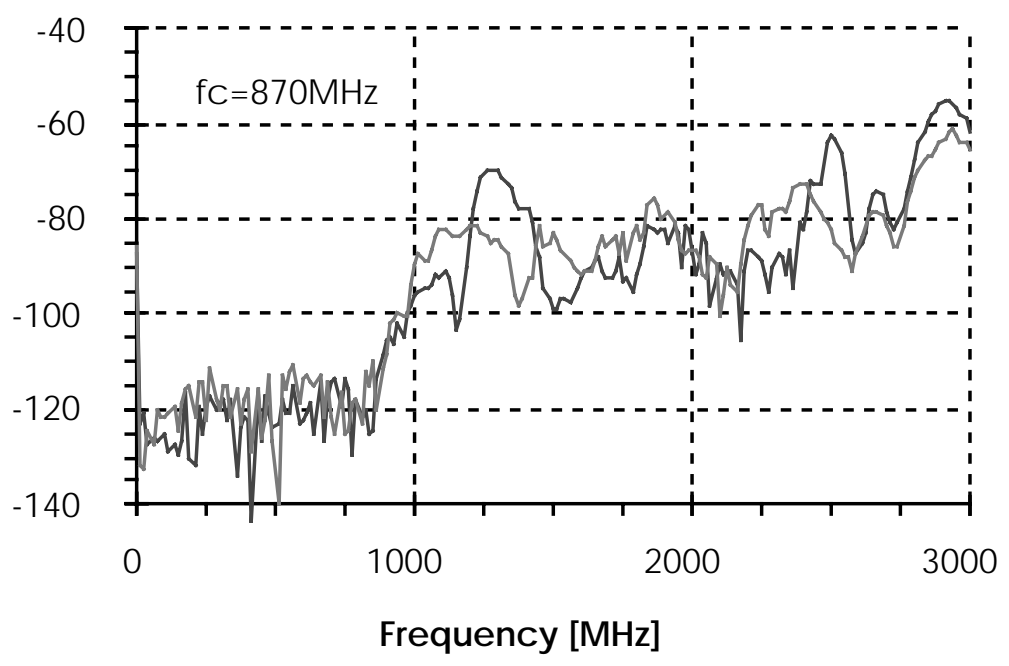

Figure 1. Coupling through Booster gradient magnets between 1" stubs at each end. Data from both the $\mathrm{F}$ and $\mathrm{D}$ magnets is shown. Microwave modes propagate through the magnet above $870 \mathrm{MHz}$. The stretched wire technique will not work above this frequency.

\section{CALCULATING IMPEDANCE}

\section{Lumped Element model}

The first approach treats the magnet as a simple lumped impedance and applies ohm's law. The real and imaginary parts of the result seem well coordinated but the magnitude is about $30 \%$ higher than the more reliable high frequency approximation. 


$$
\begin{aligned}
& S_{21}=\left(\frac{Z_{o}}{Z+Z_{o}}\right)\left(1+\frac{\left(Z+Z_{o}\right)-Z_{o}}{\left(Z+Z_{o}\right)+Z_{o}}\right)=\frac{2 Z_{o}}{Z+2 Z_{o}} \\
& Z=2 Z_{o}\left(\frac{1}{S_{21}}-1\right)
\end{aligned}
$$

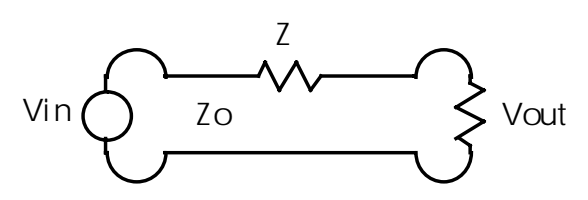

\section{6 magnets, lumped model}

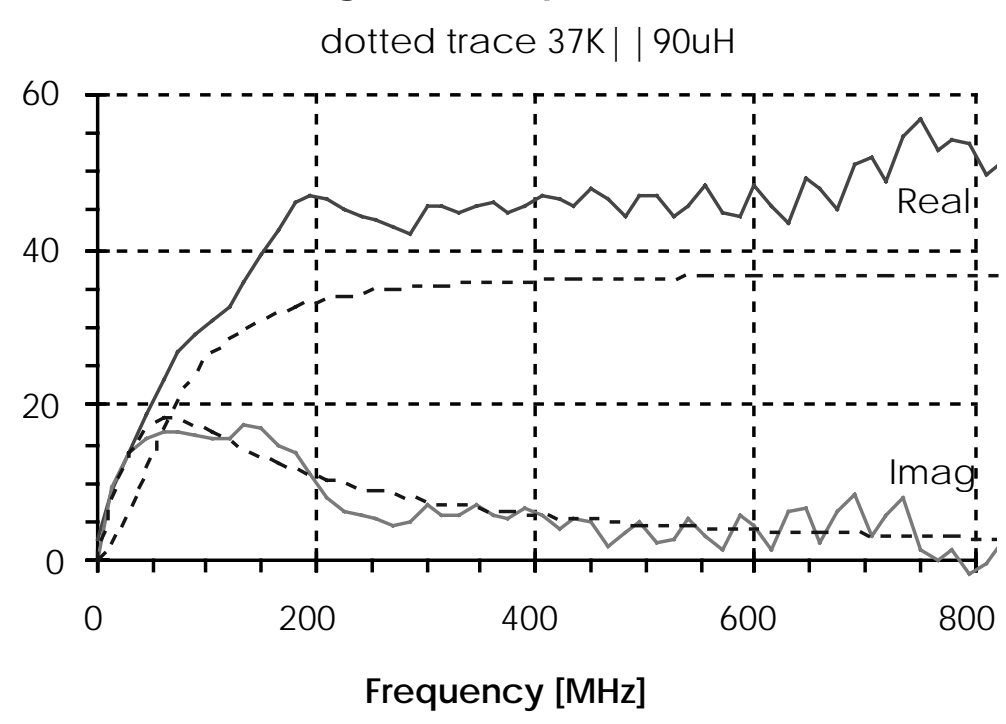

Figure 2. The total magnet impedance using Ohm's law. The dotted traces indicate the impedance of a $37 \mathrm{~K} \cdot$ resistor in parallel with a $90 \mathrm{uH}$ inductor. These values were chosen to match the imaginary impedance.

\section{High Frequency approximation}

A single $\mathrm{F}$ or D magnet has a total longitudinal resistance of about $120 \bullet / \mathrm{m}$. The $330 \bullet$ characteristic impedance of our stretched wire has $1.1 \mathrm{uH} / \mathrm{m}$. Above $17 \mathrm{MHz}(120 \bullet / 2 \bullet$ $1.1 \mathrm{uH})$, the high frequency approximation provides a good estimate of the real part of the lamination impedance. This approach does not provide the imaginary part of the impedance. The conductance, $\mathrm{G}$, between the center and outer conductors is negligible.

$$
Z_{0}=\sqrt{\frac{R+j \omega L}{G+j \omega C}} \quad \gamma=\alpha+j \beta=\sqrt{(R+j \omega L)(G+j \omega C)}
$$

high frequency approximation $R \ll \omega L$ and $G \ll \omega C$

$$
Z_{0} \approx \sqrt{\frac{L}{C}} \quad \alpha \approx \frac{R}{2 Z_{0}}+\frac{G}{2} Z_{0} \quad \beta \approx \frac{\omega}{\sqrt{L C}}=\frac{\omega}{v_{p}}
$$




$$
R=2 Z_{0} \frac{S_{21}[d b]}{8.686} \quad\left(8.686=\frac{\ln _{e} 10}{20}\right)
$$

Distributed transmission line model

The derivation below assumes that $\mathrm{L}$ and $\mathrm{C}$ are independent of frequency and can be estimated from the characteristic impedance and velocity of the stretched wire in absence of the lamination impedance. The real part is the same as found with the high frequency approximation. In order to obtain the correct imaginary part of the impedance, the flight time delay through the magnet must be removed from beta.

$$
\begin{aligned}
& \gamma=\sqrt{(R+j \omega L) j \omega C}=\alpha+j \beta \\
& \gamma^{2}=(R+j \omega L) j \omega C \\
& R=\frac{\gamma^{2}}{j \omega C}-j \omega L=\frac{\alpha^{2}-\beta^{2}+j 2 \alpha \beta}{j \omega C}-j \omega L
\end{aligned}
$$

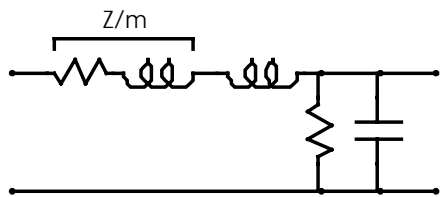

Letting $\mathrm{R}$ be a complex impedance $\mathrm{Z}$ :

$$
\begin{aligned}
& \frac{Z}{m}=2 \alpha \frac{\beta}{\omega C}-j\left(\omega L+\frac{\alpha^{2}-\beta^{2}}{\omega C}\right) \\
& \text { assume } \quad L=\frac{Z_{o}}{v} \quad C=\frac{1}{Z_{o} v} \quad \beta=\frac{\omega}{v} \\
& \frac{Z}{m}=2 \alpha Z_{o}-j \frac{\alpha^{2}}{\beta} Z_{o} \\
& Z_{\text {tot }}=2 Z_{o} \alpha l\left(1-j \frac{\alpha l}{2 \beta l}\right)
\end{aligned}
$$

The above arguments require $\mathrm{Z} / \mathrm{m} \ll \mathrm{wL} / \mathrm{m}$ of the stretched wire. The inductance of the magnet laminations is $.17 \mathrm{uH} / \mathrm{m}$ or $.10 \mathrm{uH} / \mathrm{m}$ for the $\mathrm{F}$ and $\mathrm{D}$ magnets respectively compared to $1.1 \mathrm{uH} / \mathrm{m}$ for the wire.

$$
\begin{aligned}
& \frac{V_{\text {out }}}{V_{\text {in }}}=e^{-\chi x}=e^{-\alpha x-j \beta x} \\
& \alpha x=\ln \left[\operatorname{mag}\left(\frac{V_{\text {out }}}{V_{\text {in }}}\right)\right] \quad \beta x=\operatorname{ang}\left(\frac{V_{\text {out }}}{V_{\text {in }}}\right)
\end{aligned}
$$




\section{F magnet impedance}

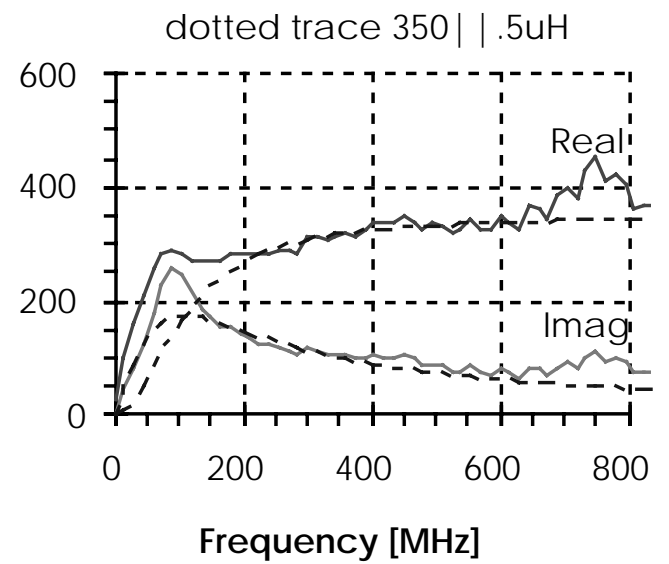

D magnet impedance

dotted trace $425 \mid$ | .3uH

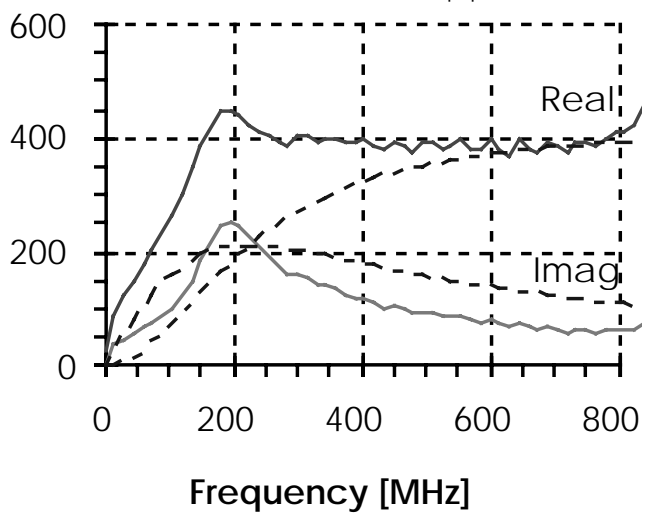

Figure 3. Comparison of lamination impedance for Booster $F$ and D gradient magnets using the transmission line model. Dotted lines indicate the impedance of a parallel $\mathrm{R} / \mathrm{L}$ circuit with values indicated.

\section{6 magnets, transmission line model}

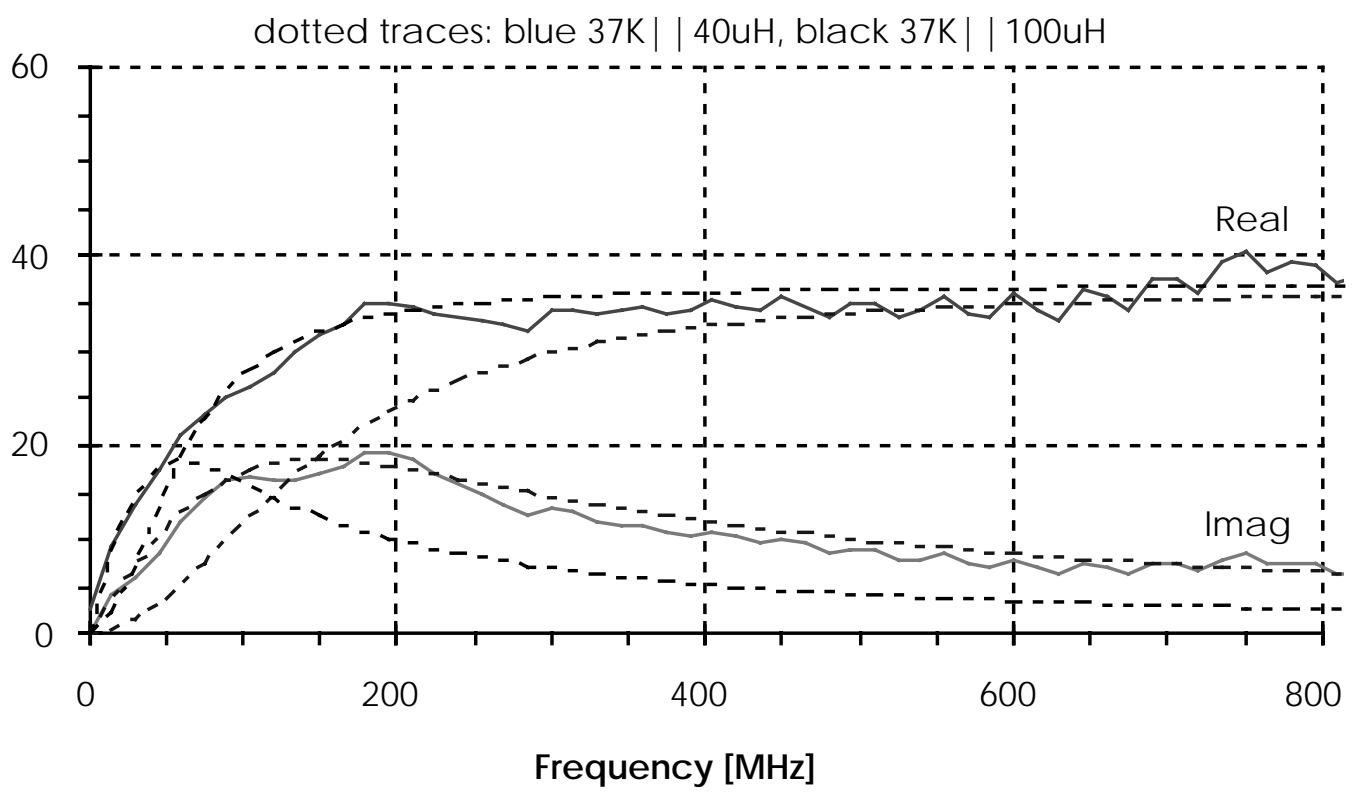

Figure 4. Total Booster magnet impedance using the transmission line model. Dotted lines indicate the impedance of parallel $\mathrm{R} / \mathrm{L}$ circuits with values indicated. The $40 \mathrm{uH}$ model matches the imaginary impedance and the $100 \mathrm{uH}$ model matches the real impedance. 


\section{BEAM MEASUREMENTS}

The beam looses energy to the real part of the lamination impedance which must be compensated with the accelerating rf system. Several attempts have been made in the past to estimate the resistive part of the magnet impedance by measuring it's effect on the beam.

The phase between the beam and the $\mathrm{rf}$ fan back near extraction was measured at several intensities. The effect was consistent with $25.5 \mathrm{~K} \bullet$.

Measuring the transition phase jump at two intensities suggested $16.7 \mathrm{~K} \bullet$

Measuring the synchrotron frequency at several intensities suggested $54 \mathrm{~K} \bullet$.

These measurements are difficult and have significant uncertainties but suggest alternate ways of verifying the real part of the magnet impedance. Bunch shape and frequency dependence of the impedance affect the result. None of these measurements have been published.

\section{IMPEDANCE REDUCING STRIPS}

Ten titanium strips .001" thick and .750" wide are stretched through the magnet and connected to ground at one end and through a $1 \mathrm{~K} \bullet$ resistor to ground at the other. Five strips lay against each pole tip. The $1 \mathrm{~K} \cdot$ resistor reduces the currents driven by the normal $15 \mathrm{~Hz}$ magnetic program of the Booster. The DC resistance of each strip is about 10 •. A 6" wide ribbon of kapton is used to insulate the titanium strips from the magnet laminations. Periodically along the length a small piece of kapton is attached to the larger ribbon to trap the titanium strips and prevent them from vibrating or moving when the magnets are driven at $15 \mathrm{~Hz}$. Each strip is tensioned to 16 pounds with a "fish" scale. Under tension, the strips stretch by $1 / 8$ to $1 / 4 "$. 


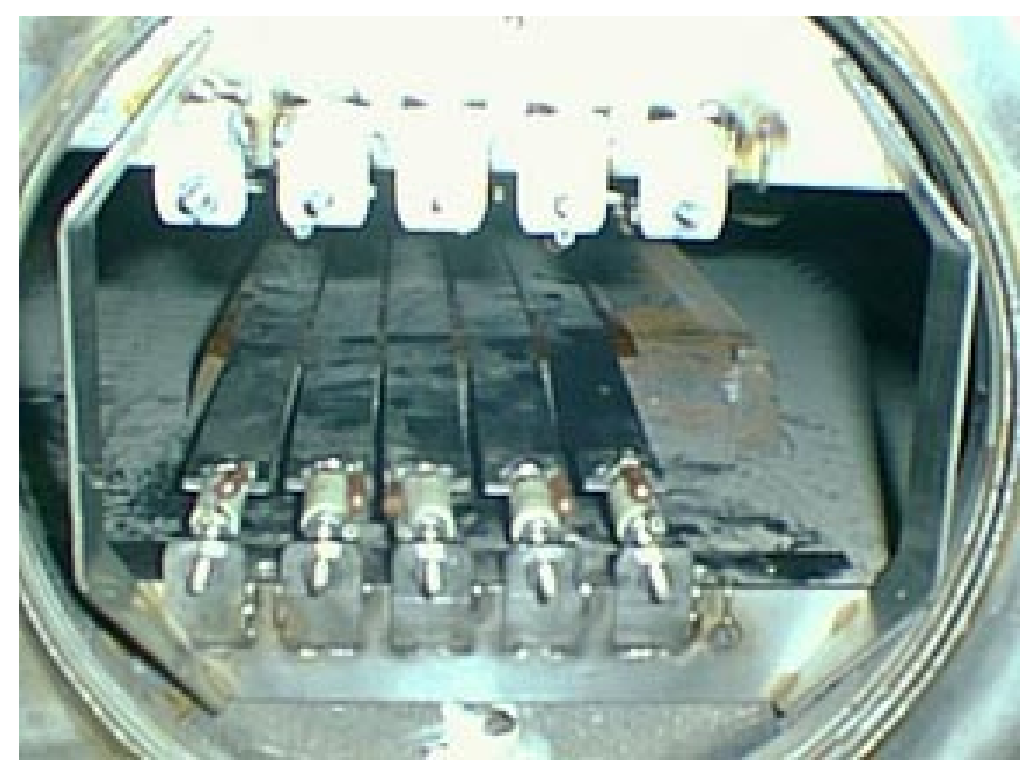

Figure 5. Titanium strips installed in a D style Booster magnet. Note the ceramic standoffs and $1 \mathrm{~K} \cdot$ resistors used at one end. The opposite ends of the strips are electrically connected to ground.

\section{F\&D magnet impedance with strips}

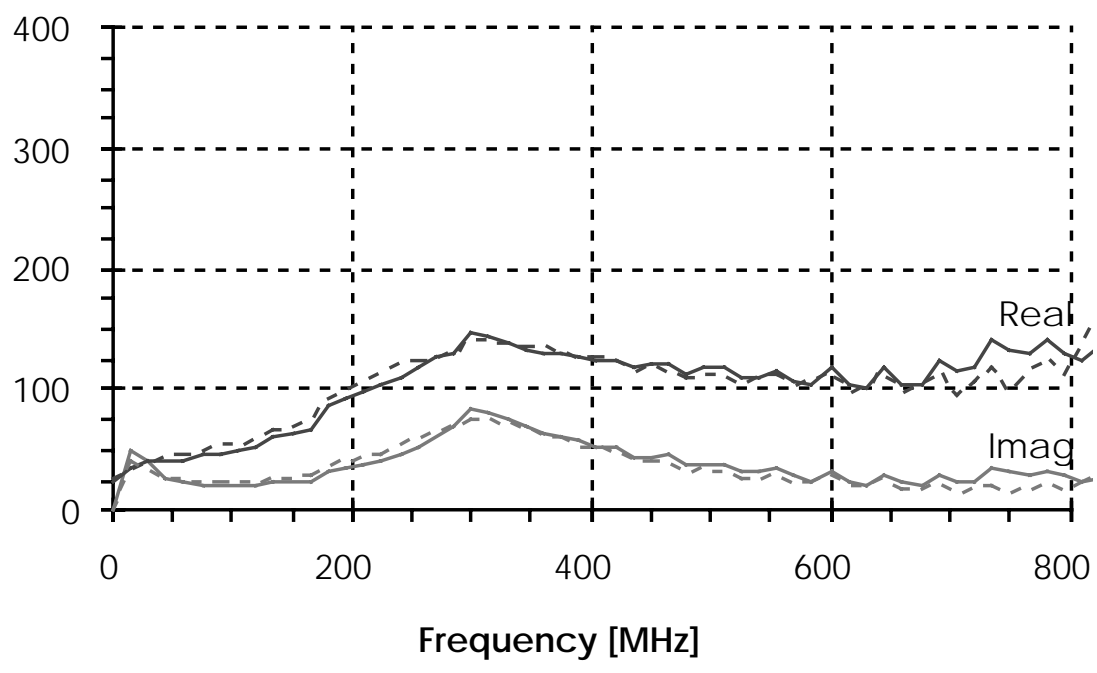

Figure 6. Impedance of one Booster magnet with ten titanium strips installed. The strips are connected to ground through $1 \mathrm{~K} \bullet$ resistors at one end. The $100 \bullet$ impedance is from the ten $1 \mathrm{~K} \bullet$ resistors in parallel. The solid and dotted curves are for an F and D magnet respectively. 
The 100• impedance measured with the strips in place reflects the parallel combination of the ten $1 \mathrm{~K} \cdot$ resistors at one end of the strips. This agreement provides some validity for the stretched wire measurement.

The effectiveness of two 18 gauge insulated wires, one on each pole tip, was also evaluated. Both ends were tied directly to ground. The titanium strips were significantly better.

\section{LOW FREQUENCY INDUCTANCE}

The laminations make a complete magnetic path around the beam. At low frequency, the inductance can be substantial.

$$
\begin{aligned}
& L=N \frac{\phi}{I} \quad \phi=\frac{m m f}{\text { Reluctance }} \quad m m f=N I \quad \text { Reluctance }=\frac{l}{\mu A} \\
& L=N^{2} \mu \frac{A}{l} \quad N=1, \quad u=100 \mu_{0}, \quad A=2.5^{\prime \prime} \times 113.75^{\prime \prime}, \quad l=52^{\prime \prime} \\
& L \approx 17.5 \mu \mathrm{H} / \text { magnet } \quad \text { (at low frequency) }
\end{aligned}
$$

Eddy currents in the laminations will reduce this inductance above $10 \mathrm{KHz}$.

\section{DISCUSSION}

The current measurement differs slightly from previous estimates. One cause is the higher characteristic impedance of the wire. The high frequency approximation works best when $Z<<j w L$ where $L$ is proportional to the characteristic impedance squared. Previous measurements attempted to follow the sagitta of the magnet with a 1.125" diameter copper pipe and a 1/16" diameter copper plated welding rod. The smaller wire (larger characteristic impedance) and better test equipment used in the present measurements should provide more accurate results. 


\section{One Booster D magnet c irca 1986}

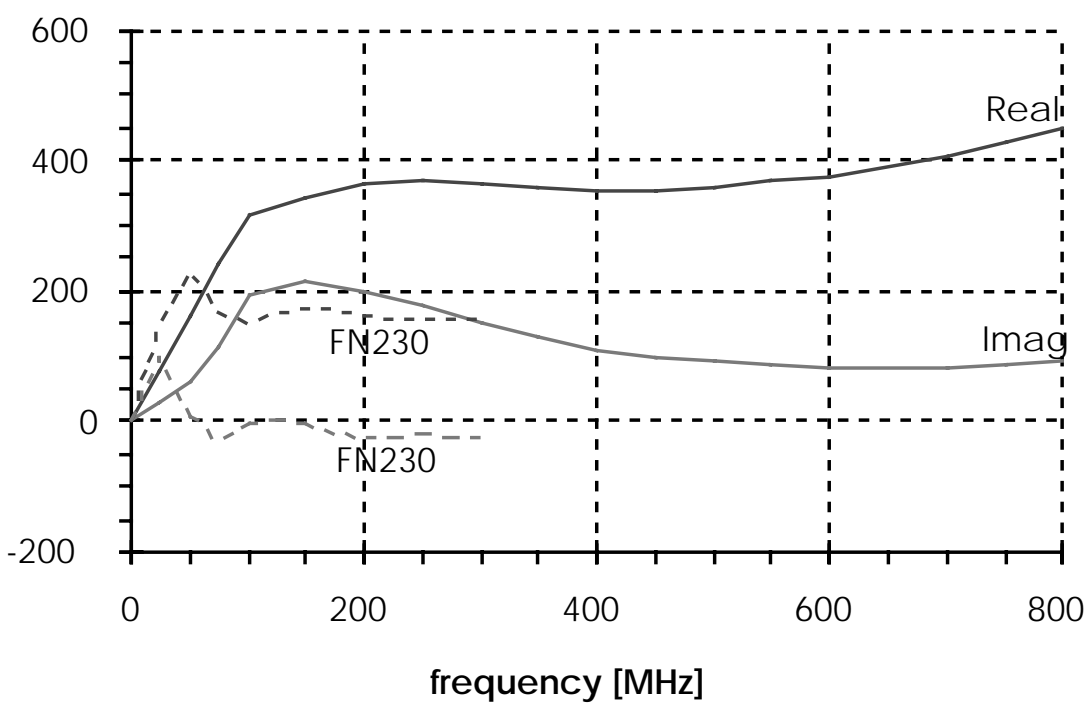

Figure 7. Measurements of one Booster D magnet done in 1986 using a 1/16" wire compared with calculated values from FN230, [3].

The lamination impedance was calculated by treating the magnet poles as a shorted transmission line $[1,2,3,4,5]$. Laminations are electrically connected through \#8 copper wires pinched between the $1 \times 1.5$ " key and the key way at the top and bottom of the magnet laminations, drawing numbers 2538 an 2539. The keys run along the entire length of the magnet and are welded to the end packs. The parameters used to estimate the impedance are:

laminations:

$\begin{array}{ll}\text { laminations /mag } & 4483 \\ \text { thickness } & .0250^{\prime \prime}(24 \text { gauge }) \\ \text { resistivity } & 20 \mathrm{u} \bullet-\mathrm{cm} \\ \text { permitivity } & 100\end{array}$

dielectric

$\begin{array}{ll}\text { gap } & .000375 " \\ \text { resistivity } & 100 \mathrm{~K} \cdot-\mathrm{cm} \\ \text { permitivity } & 4.7\end{array}$




\section{REFERENCES:}

1. Snowdon, S.C.; "Wave Propagation Between Booster Laminations Induced by Longitudinal Motion of Beam"; Fermilab TM-277; November 3, 1970.

2. Ruggiero, A.G.; "Longitudinal Space Charge Forces Within a Bunched Beam in the Presence of Magnetic Lamination"; Fermilab FN-220; January 4, 1971.

3. Ruggiero, A.G.; "Energy Loss due to the Resistive Magnet Lamination in the NAL Booster"; Fermilab FN-230; May 15, 1971.

4. Gluckstern, R.; "Coupling Impedance and Energy Loss with Magnet Laminations"; Fermilab TM-1374; November 1985.

5. Shafer, R.E.; "Coupling Impedance of Laminated Magnets in the Booster"; Fermilab TM-1408; July 11, 1986

\section{DRAWINGS:}

D Magnet Assembly 0321-ME-2538

F Magnet Assembly 0321-ME-2539

D Magnet Lamination 0321-MD-2127

F Magnet Lamination 0321-MD-2126

D Magnet Lamination Profile 0321-MD-2190

F Magnet Lamination Profile 0321-MD-2188

\section{MISCELLANEOUS DATA:}

\begin{tabular}{|c|c|}
\hline lamination thickness & $.0250 "$ \\
\hline gap & $.000375 "$ \\
\hline laminations /m & 1552 \\
\hline$F$ magnet & \\
\hline height at center & $1.640^{\prime \prime}$ \\
\hline height at 1 " from center & $1.74 "$ \\
\hline sagitta & $\pm .503^{\prime \prime}$ \\
\hline magnet length & $125.828 "$ \\
\hline lamination length & 113.741" \\
\hline D magnet & \\
\hline height at center & $2.250 "$ \\
\hline height at 1 " from center & 2.42" \\
\hline sagitta & $\pm .428 "$ \\
\hline magnet length & $126.328 "$ \\
\hline lamination length & 113.741" \\
\hline
\end{tabular}


TABULATED IMPEDANCE FOR PRESENT MEASUREMENT

\begin{tabular}{|c|c|c|c|c|c|c|}
\hline \multirow[b]{2}{*}{$\mathrm{MHz}$} & \multicolumn{2}{|c|}{ s/n F47 } & \multicolumn{2}{|c|}{$\mathrm{s} / \mathrm{n} \mathrm{D} 10$} & \multicolumn{2}{|c|}{$48 x F+48 x D$} \\
\hline & $\operatorname{Re}[\Omega]$ & $\operatorname{Im}[\Omega]$ & $\operatorname{Re}[\Omega]$ & $\operatorname{Im}[\Omega]$ & $\operatorname{Re}[\mathrm{K} \Omega]$ & $\operatorname{Im}[\mathrm{K} \Omega]$ \\
\hline 0 & 25 & 0 & 30 & 0 & 2.6 & .0 \\
\hline 15 & 101 & 45 & 90 & 39 & 9.2 & 4.1 \\
\hline 30 & 161 & 81 & 122 & 48 & 13.6 & 6.2 \\
\hline 45 & 212 & 125 & 151 & 58 & 17.4 & 8.8 \\
\hline 60 & 257 & 181 & 180 & 67 & 20.9 & 11.9 \\
\hline 75 & 282 & 227 & 205 & 74 & 23.4 & 14.5 \\
\hline 90 & 289 & 257 & 235 & 86 & 25.1 & 16.4 \\
\hline 105 & 282 & 248 & 267 & 102 & 26.3 & 16.8 \\
\hline 120 & 272 & 218 & 303 & 121 & 27.6 & 16.3 \\
\hline 135 & 272 & 188 & 348 & 150 & 29.8 & 16.2 \\
\hline 150 & 270 & 171 & 387 & 183 & 31.6 & 17.0 \\
\hline 165 & 269 & 157 & 418 & 217 & 33.0 & 17.9 \\
\hline 180 & 283 & 153 & 445 & 248 & 34.9 & 19.2 \\
\hline 195 & 284 & 144 & 446 & 254 & 35.0 & 19.1 \\
\hline 210 & 284 & 137 & 439 & 249 & 34.7 & 18.5 \\
\hline 225 & 282 & 127 & 424 & 229 & 33.9 & 17.1 \\
\hline 240 & 285 & 122 & 411 & 208 & 33.4 & 15.8 \\
\hline 255 & 287 & 117 & 403 & 190 & 33.1 & 14.8 \\
\hline 270 & 287 & 112 & 393 & 174 & 32.7 & 13.8 \\
\hline 285 & 285 & 104 & 384 & 158 & 32.1 & 12.6 \\
\hline 300 & 311 & 116 & 407 & 164 & 34.5 & 13.4 \\
\hline 315 & 312 & 113 & 404 & 157 & 34.4 & 13.0 \\
\hline 330 & 309 & 105 & 396 & 145 & 33.8 & 12.0 \\
\hline 345 & 316 & 104 & 399 & 140 & 34.3 & 11.7 \\
\hline 360 & 321 & 106 & 402 & 138 & 34.7 & 11.7 \\
\hline 375 & 316 & 98 & 391 & 126 & 33.9 & 10.8 \\
\hline 390 & 324 & 99 & 390 & 120 & 34.3 & 10.5 \\
\hline 405 & 338 & 106 & 397 & 120 & 35.3 & 10.8 \\
\hline 420 & 335 & 102 & 390 & 113 & 34.8 & 10.3 \\
\hline 435 & 335 & 98 & 381 & 103 & 34.3 & 9.6 \\
\hline 450 & 349 & 105 & 393 & 106 & 35.6 & 10.1 \\
\hline 465 & 339 & 99 & 387 & 101 & 34.8 & 9.6 \\
\hline 480 & 324 & 87 & 376 & 91 & 33.6 & 8.5 \\
\hline 495 & 338 & 90 & 392 & 95 & 35.0 & 8.9 \\
\hline 510 & 335 & 88 & 395 & 96 & 35.0 & 8.8 \\
\hline 525 & 317 & 76 & 383 & 87 & 33.6 & 7.9 \\
\hline 540 & 328 & 77 & 388 & 86 & 34.4 & 7.9 \\
\hline 555 & 346 & 85 & 400 & 90 & 35.8 & 8.4 \\
\hline 570 & 325 & 75 & 381 & 81 & 33.9 & 7.5 \\
\hline 585 & 324 & 70 & 378 & 76 & 33.7 & 7.0 \\
\hline 600 & 353 & 81 & 397 & 82 & 36.0 & 7.9 \\
\hline 615 & 336 & 74 & 379 & 74 & 34.3 & 7.1 \\
\hline 630 & 323 & 64 & 368 & 67 & 33.2 & 6.3 \\
\hline 645 & 366 & 80 & 396 & 75 & 36.6 & 7.5 \\
\hline 660 & 360 & 79 & 383 & 70 & 35.7 & 7.2 \\
\hline
\end{tabular}




\begin{tabular}{|l|ll|ll|ll|}
675 & 341 & 67 & 373 & 64 & 34.3 & 6.3 \\
690 & 388 & 84 & 395 & 70 & 37.6 & 7.4 \\
705 & 401 & 92 & 386 & 66 & 37.8 & 7.6 \\
720 & 379 & 80 & 375 & 60 & 36.2 & 6.7 \\
735 & 430 & 99 & 391 & 64 & 39.4 & 7.8 \\
750 & 451 & 115 & 394 & 64 & 40.6 & 8.6 \\
765 & 411 & 96 & 389 & 60 & 38.4 & 7.5 \\
780 & 421 & 98 & 399 & 62 & 39.4 & 7.7 \\
795 & 407 & 94 & 410 & 64 & 39.2 & 7.6 \\
810 & 364 & 74 & 410 & 62 & 37.2 & 6.5 \\
\hline
\end{tabular}

page 12 